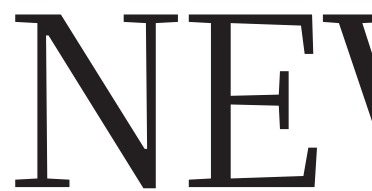

BIOTECHNOLOgY Sleuthing in a bid to solve a GM wheat whodunnit p.262
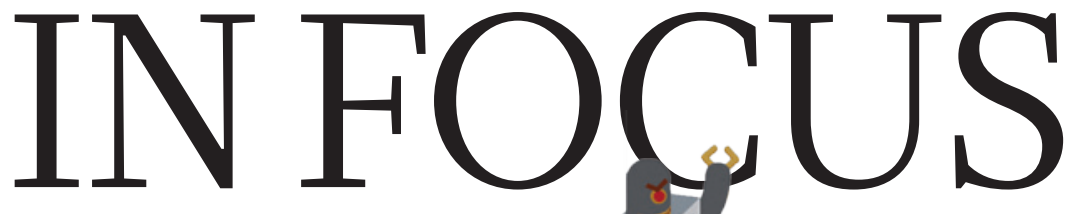

PHARMACEUTICALS New uses for old drugs in translational gamble by the NIH $\mathbf{p . 2 6 3}$
SPACE Lasers set to open up communications floodgates $\mathbf{p . 2 6 6}$
EDUCATION Lab practicals and politics, taught online $\mathbf{p . 2 6 8}$

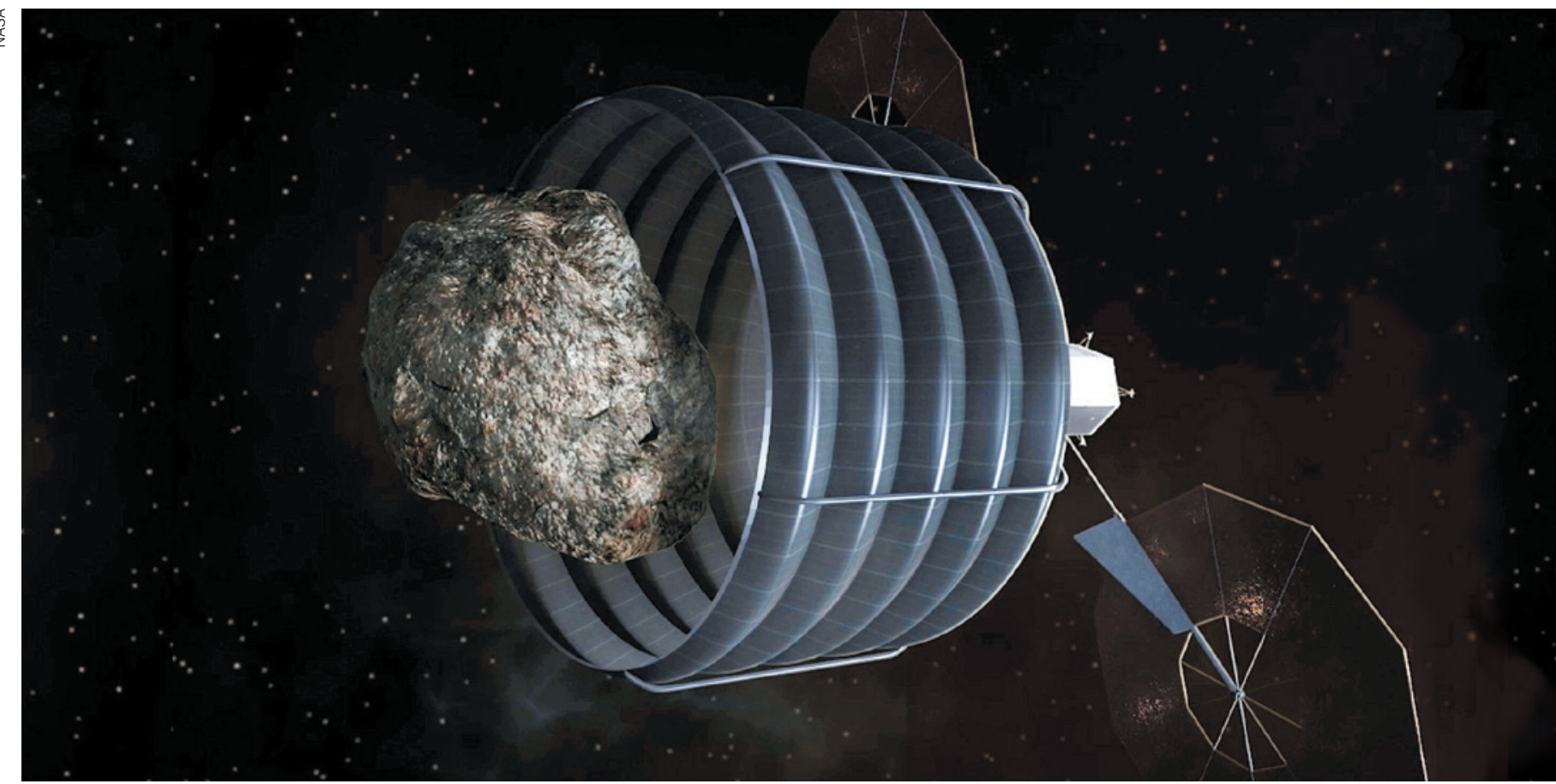

NASA's asteroid-capture spacecraft (concept illustration) would envelope a 10-metre-wide rock in an inflatable bag and tug it close to the Moon.

\title{
Asteroid plan looks rocky
}

\section{NASA mission to retrieve a small space rock could be tripped up by lack of candidates.}

\section{BY ALEXANDRA WITZE}

$\mathrm{N}$ ASA has plans to grab an asteroid and tow it near to the Moon for astronauts to visit. But finding a target space rock may be the agency's biggest challenge. Only a handful of known asteroids would suit NASA's requirements, and current sky surveys are not tuned to find many more candidates.

"There's great scepticism, among both the science community and the public, that this can actually be pulled off," says Jim Bell, a planetary scientist at Arizona State University in Tempe, who attended a workshop on 9 July at the US National Academy of Sciences in Washington DC. The workshop marked the first chance for asteroid scientists to voice their doubts to NASA officials.

US President Barack Obama proposed the asteroid initiative in April, as part of his 2014 budget request to Congress. If the mission gets funded, NASA would expand its surveys for large, hazardous space rocks so that the agency might find an asteroid that is small enough, solid enough and on a trajectory that would allow it to be met by a spacecraft launching as early as 2017.

Details of the mission remain fuzzy, but at the workshop, scientists revealed the first hard numbers on how many asteroids might be suitable to snatch. Of the more than 10,000 known near-Earth asteroids, 370 are small enough for capture, at roughly 10 metres across, says Paul Chodas, an asteroid tracker at NASA's Jet Propulsion Laboratory in Pasadena, California. But of those 370, only 14 have a suitable orbit. Just four have been studied well enough for scientists to know something about the bodies' surface texture and spin rate. NASA wants to find a cohesive body spinning at less than two revolutions per minute, to minimize the risk of any damage to the spacecraft.

If NASA picks up the pace of its sky surveys, astronomers should find at least 15 more 10-metre targets over the next three to four years, says Chodas, and at least half of those are likely to be in the right orbit. But that would require the agency to boost funding to the survey programmes, which currently focus on finding rocks that are 140 metres across or larger. To spot 10-metre-class rocks, "we have to go fainter", says Timothy Spahr, director of the Minor Planet Center in Cambridge, Massachusetts, which catalogues near-Earth asteroid discoveries. Going fainter means, for instance, adding two more cameras to the Catalina Sky Survey, based at the University of Arizona 
in Tucson. The survey has discovered most of the small near-Earth asteroids so far. These cameras - planned for mid-2014 - would double the survey's field of view and increase the chances of catching a faint small object, says Spahr.

NASA also plans to restart the Wide-field Infrared Survey Explorer, a spacecraft that has been in hibernation since 2011, to hunt for more asteroids. Two facilities slated for Hawaii - the Pan-STARRS-2 telescope and the ATLAS telescope array - could also add to the effort.

The extra eyes are crucial because nearEarth asteroids often vanish from view within days of a sighting. On discovery, astronomers must quickly marshal followup observations with radar and infrared telescopes to learn more about the rock's size, shape and composition.

Engineers at NASA's Johnson Space Center in Houston, Texas, are already working on several mission designs for the robotic capture craft, which would need to grapple with an asteroid weighing around 400 tonnes - about the mass of the International Space Station (ISS). The xenon-ion thrusters used to get to the asteroid, and the inflatable rip-resistant bag used to capture it, are straightforward components. The bigger issue is finding a target and building the spacecraft in time for launch, says Andrew Thomas, an astronaut at Johnson who works on the project. "It's pretty brazen, if you think about it," he says.

A 2017 launch would allow the spacecraft to drag the target asteroid to a position near the Moon by 2021. In theory, astronauts could then visit the asteroid, peel back or cut the bag and take rock samples back to Earth.

NASA expects the mission to cost between US\$1 billion and $\$ 2.6$ billion. Agency officials are careful to emphasize that the goal is not science, but rather to give astronauts practice in going into deep space, where they must contend with harsher radiation environments than on missions to the ISS. "If our goal is to get to Mars in the 2030 time frame, we're going to have to be aggressive with this upfront stuff," says William Gerstenmaier, NASA's associate administrator for human exploration and operations.

It is not yet clear whether Obama's plan will be paid for by Congress, which has been locked in a battle with the administration over agency goals ever since NASA gave up former President George W. Bush's vision of returning to the Moon (see Nature 492, 161-162; 2012). A bill proposed by a congressional subcommittee on space in the Republican-dominated House of Representatives would cancel all funding for the asteroid initiative.

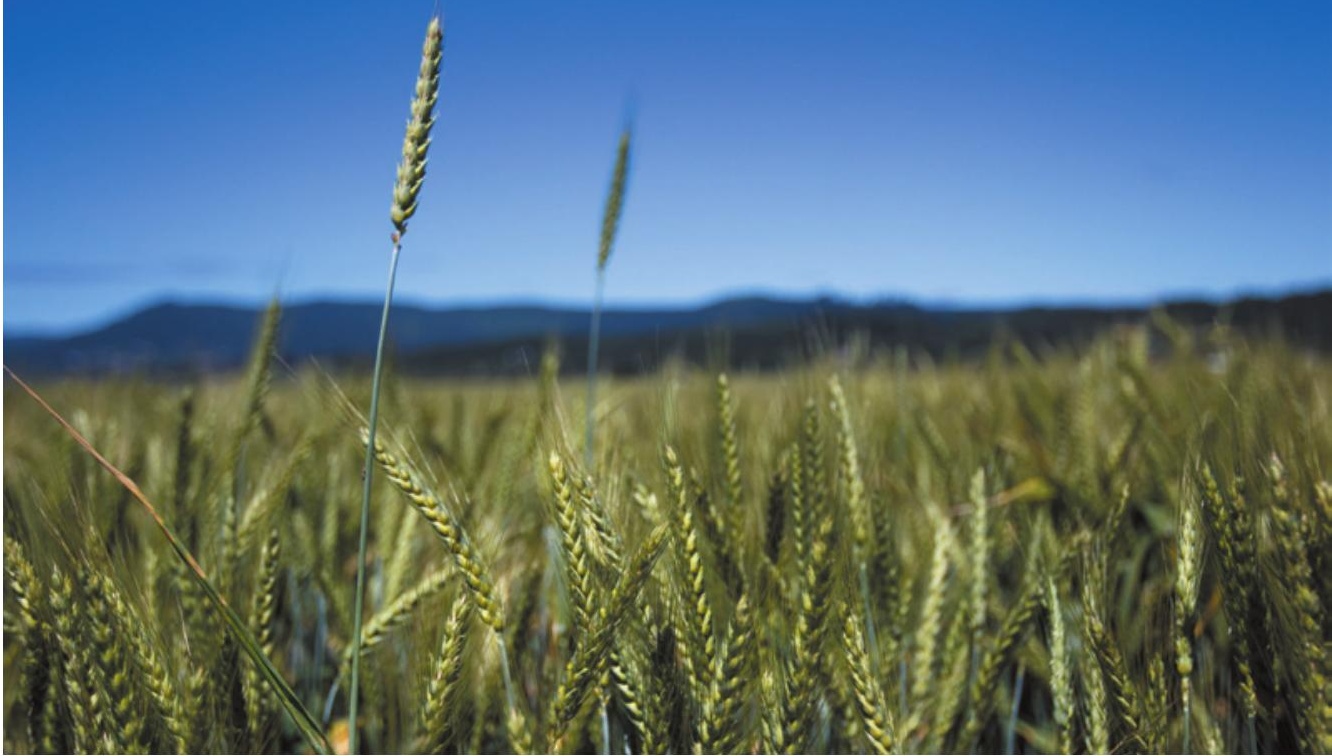

Wheat in a test field at Oregon State University where scientists are helping to identify a rogue GM crop.

BIOTECHNOLOGY

Hunt for mystery
GM wheat hots up

Investigators hope to track origins of the transgenic crop.

\section{BY HEIDI LEDFORD}

I t has been nearly three months since an Oregon farmer discovered unapproved transgenic wheat in a commercial wheat field, triggering bans on imports of US wheat into Japan and South Korea. The harvest season has now begun, and with the contamination proving to be an isolated event, imports into South Korea have resumed.

But as an army of combines marches across the wheat fields of eastern Oregon, the mystery of the transgenic intruders is fresh in the minds of investigators at the US Department of Agriculture (USDA), who are trying to trace the plants' provenance to a particular research plot. Those close to the investigation say that the identity of the variety in question could emerge in the coming weeks, providing a much-needed breakthrough in this agricultural whodunnit. It could point to the cause of the release, which some have suggested could be activist sabotage. "We may never know who actually released it," says James Moyer, director of the Agricultural Research Center at Washington State University in Pullman. "But if they know the genotype of those plants, they will be able to narrow it down quite a bit."

Within a month of the discovery in May, USDA scientists had traced the origin of the plants to a line of herbicide-resistant 'Roundup $\rightarrow$ NATURE.COM For more on GM crops see Nature's special issue: go.nature.com/gafvrp
Ready' wheat called MON71800, developed by the agricultural company Monsanto, based in St Louis, Missouri. Monsanto killed the project in 2005 over farmers' worries that overseas customers would not buy US wheat if it contained transgenic varieties. No GM wheat has yet been approved to be grown commercially in the United States. The company says that all seed from the field trials - conducted on more than 400 hectares in 16 states (see 'Sifting for GM wheat') - was accounted for and either secured or destroyed.

Monsanto had shipped MON71800 seed to breeders around the country for crossing with commercial varieties optimized for each region's climate, day length and disease profile. Now, the USDA investigators are sifting through hundreds of markers to try to match the genetic signature of the contaminant Oregon wheat with one of the varieties from the 256 field tests registered with the USDA. An origin near Oregon could hint at an accidental escape; seeds from farther afield could mean that someone had intentionally saved seed and released it.

But pinning down the variety is difficult, says Michael Firko, the head of biotechnology regulation at the USDA's Animal and Plant Health Inspection Service. USDA scientists have a limited amount of plant DNA to work with, and are proceeding cautiously in testing for singlebase differences or variations in the number of copies of a repeated sequence that are unique to the various strains of wheat. "It takes time," says Firko, "but we're making good progress." 